\title{
A Revelação da Homossexualidade na Família: Revisão Integrativa da Literatura Científica
}

\author{
Geysa Cristina Marcelino Nascimento*, 1 \\ Orcid.org/0000-0002-7359-866X \\ Fabio Scorsolini-Comin ${ }^{2}$ \\ Orcid.org/0000-0001-6281-3371
}

${ }^{1}$ Universidade Federal do Triângulo Mineiro, Uberaba, MG, Brasil

${ }^{2}$ Escola de Enfermagem de Ribeirão Preto, Universidade de São Paulo, Ribeirão Preto, SP, Brasil

\section{Resumo}

A revelação da homossexualidade (coming out) no contexto familiar é um tema ainda pouco investigado na literatura científica. O presente estudo teve por objetivo apresentar uma revisão integrativa da literatura científica a fim de compreender quais as repercussões da revelação da orientação sexual nas relações familiares de jovens adultos homossexuais. A partir das bases LILACS, MEDLINE, PePSIC, PsycINFO e SciELO (janeiro/2006-maio/2016), foram recuperados 38 artigos. Predominam estudos qualitativos com pessoas homossexuais, tanto com gays quanto com lésbicas, e outros que ressaltam o papel da família diante do coming out, o que permite conhecer e identificar questões ligadas ao processo de revelação ou ocultação da homossexualidade. Estudos também avaliam a participação e os sentimentos que acarretam a revelação nas famílias, sendo observado contextos em que os conflitos prevaleceram e outros nos quais houve acolhimento por parte dos entes. Também foram observados casos em que jovens buscaram a rede social como uma referência de apoio no processo de coming out. Nota-se a necessidade de novos estudos acerca da temática, ampliando a visibilidade desse processo.

Palavras-chave: Coming out, comportamento sexual, família, homossexuais.

\section{Revealing one's Homosexuality to the Family: An Integrative Review of the Scientific Literature}

\begin{abstract}
Coming out in the family context is a subject that has not been widely investigated in the scientific literature. This study aimed to present an integrative review of the scientific literature to understand the repercussions of young adult homosexuals revealing their sexual orientation to their families. A total of 38 articles were retrieved from the LILACS, MEDLINE, PePSIC, PsycINFO and SciELO databases (January/2006-May/2016). Qualitative studies with homosexuals predominate, both with gays and lesbians, and others that highlight the role of the family in the coming out, which allows to know and

* Endereço para correspondência: Departamento de Enfermagem Psiquiátrica e Ciências Humanas, Escola de Enfermagem de Ribeirão Preto da Universidade de São Paulo, Avenida dos Bandeirantes, 3900, Monte Alegre, Ribeirão Preto-SP, CEP: 14040-902.

Suporte: Coordenação de Aperfeiçoamento de Pessoal de Nível Superior (CAPES).
\end{abstract}


identify issues related to the process of revelation or concealment of homosexuality. The studies also assessed the participation and feelings resulting from coming out to the family, with contexts in which conflicts prevailed observed and others in which there was acceptance by the family members. Cases in which young people turned to social networks as a support reference in the coming out process were also observed. There is a notable need for new studies on the theme, increasing the visibility of this process.

Keywords: Coming out, sexual behavior, family, homosexuals.

\section{La Revelación de la Homosexualidad en la Familia: Revisión Integra de la Literatura Científica}

\section{Resumen}

La revelación de la homosexualidad (coming out) en el contexto familiar aun es un tema poco investigado en la literatura científica. El presente estudio tuvo por objetivo presentar una revisión integradora de la literatura científica a fin de comprender cuales son las repercusiones de la revelación de la orientación sexual en las relaciones familiares de jóvenes y adultos homosexuales. A partir de las bases LILACS, MEDLINE, PePSIC, PsycINFO y SciELO (enero/2006-mayo/2016), fueron recuperados 38 artículos. Predominan estudios cualitativos con los homosexuales. Los estudios también evalúan la participación de los sentimientos que conducen la revelación en las familias, siendo observados contextos en que los conflictos prevalecen y otros en los cuales hubo acogimiento por parte de los entes. También fueron observados casos en que los jóvenes buscaron la red social como una referencia de apoyo en el proceso de coming out. Se nota la necesidad de nuevos estudios acerca de la temática, ampliando la visibilidad de ese proceso.

Palabras clave: Coming out, comportamiento sexual, familia, homosexuales.

Na contemporaneidade, nota-se uma maior visibilidade nas questões que abarcam as relações amorosas e seus modos de expressão tanto afetivas quanto de intimidade sexual. Tal movimento é advindo da retroalimentação das mudanças culturais e históricas e dos padrões que delimitam as relações sociais, o que possibilita maiores discussões acerca das questões de gênero e das sexualidades, bem como suas repercussões na vida dos homossexuais e suas famílias (Lomando \& Wagner, 2009; Nascimento, Scorsolini-Comin, Fontaine, \& Santos, 2015; Prado \& Machado, 2012). Os estudos acerca a temática LGBT (lésbicas, gays, bissexuais, travestis, transexuais e transgêneros) se configuram hoje como um campo consolidado de pesquisa, adquirindo cada vez mais espaço no âmbito acadêmico e legitimidade junto aos movimentos sociais (Lomando, Wagner, \& Gonçalves, 2011).

Sendo assim, temas relacionados às questões de gênero e sexualidade repercutem a partir das lutas sociais, como as relacionadas ao movi- mento LGBT, que vem, por meio de suas ações, conquistando espaços e direitos para este público (Victora \& Knauth, 2004). No que tange ao gênero, para Butler (2003), é um processo que não apresenta origem nem fim, sendo considerado algo que é "feito" e não algo que se "é". A autora afirma que "todo gênero é, por definição, não natural" (p. 35), entendendo que sexo, gênero e sexualidade não estabelecem uma relação mútua. De acordo com Martins, Romão, Lindner e Reis (2010), a sexualidade pode ser compreendida como "elaborações culturais sobre os prazeres e os intercâmbios sociais e corporais que compreendem desde o erotismo, o desejo e o afeto, até noções relativas à saúde, à reprodução, ao uso de tecnologias e ao exercício do poder na sociedade" (p. 9). Tais formas estão ligadas às dimensões da vida social na reprodução e produção dos valores referentes à vida coletiva (Prado \& Machado, 2012).

As relações homoafetivas vêm ganhando espaço e visibilidade na literatura científica, em 
uma postura de se combater preconceitos e promover uma cultura de maior tolerância e respeito à diversidade (Nascimento et al., 2015). No que tange à revelação da orientação sexual (outness - refere-se ao assumir-se homossexual para si mesmo e coming out refere-se ao processo da revelação da orientação sexual, comumente chamado de "sair do armário") e as relações familiares, nota-se que é um desafio para o indivíduo que quer contar para a família, uma vez que há o temor de ser rejeitado pelos familiares e pela sociedade. Pensa-se na frustração que poderá causar à família por não corresponder às expectativas deles, tendo em vista que, de modo heteronormativo, a homossexualidade contraria a construção sociocultural a respeito de si mesmo e do homem e da mulher heterossexuais, na qual o esperado era a afirmação da continuação de uma sociedade patriarcal, racionalizadora, higienizada e preocupada de modo a não propagar qualquer tipo de ameaça de grupos minoritários que afetem a moral das famílias tradicionais (Maffesoli, 2007; Miskolci, 2015). Para Martins et al. (2010), a heteronormatividade é compreendida como uma "expressão utilizada para descrever ou identificar uma suposta norma social relacionada ao comportamento padronizado heterossexual" (p. 12), ideia complementada por Méllo (2012), que a relaciona diretamente com os papéis de gênero esperados para homens e mulheres.

Assim, a família é vista como o maior alicerce para que o sujeito possa revelar sua orientação sexual perante si mesmo e a sociedade. Contudo, podem estar mais expostos a experiências de preconceitos e homofobia, o que pode associar a problemas de saúde mental e física (Zimmerman, Darnell, Rhew, Lee, \& Kaysen, 2015). Em contrapartida, a ocultação da orientação sexual pode acarretar sérios problemas de diversas ordens, como, por exemplo, sociais, comportamentais e psíquicos, o que limita o acesso à busca por apoio social e ocasionar a autoestima baixa (Meyer, 2003). A revelação da orientação sexual pode permitir que o sujeito se sinta protegido pela família e pelas pessoas que o cercam na sociedade e que mantenham bons resultados de saúde de modo geral, além de vivenciar e sen- tir o apoio recebido (Corliss, Austin, Roberts, \& Molnar, 2009).

Vale ressaltar que o processo do coming out passa por uma série de movimentos, desde a "saída do armário" até a persistência em continuar "no armário" mesmo o(a) homossexual sendo assumido(a). Isto se justifica por uma série de questões sociais, como, por exemplo, o sigilo da homossexualidade perante os colegas de trabalho ou para ser incluso em um determinado grupo. Tal movimento alimenta a ideia de que os sentimentos e desejos por pares homossexuais devem ser mantidos em "segredo, conformando-o a expectativas historicamente criadas de que essas relações deveriam permanecer invisíveis no espaço público e restritas à vida privada dos envolvidos" (Miskolci, 2013, p. 303), ou seja, perante a sociedade o sujeito "macho" deve impor sua masculinidade, deixando sua sexualidade de lado e reforçando a opressão gay.

A homossexualidade, quando revelada à família, pode vir a ser um problema nas relações. Para os jovens que decidem pelo coming out, a frustração pode ser grande diante do impacto causado aos familiares, que, em muitos casos, não conseguem tornar o ambiente acolhedor, do modo que é esperado por esta instituição. Comumente, os familiares exteriorizam agressões, ameaças e outros muitos tipos de violências que evidenciam a intolerância, frustração e medo por se depararem com a existência de um(a) filho(a) homossexual (Balsam \& Mohr, 2007; Detrie \& Lease, 2007; Rosario, Schrimshaw, \& Hunter, 2011).

Pode-se pensar também na dificuldade dos pais e familiares em lidarem com estas questões, sendo que muitas vezes eles mesmos estão cercados por medos e não se sentem à vontade para conversarem e lidarem com questões ligadas à sexualidade de um modo geral (Zimmerman et al., 2015). A partir desse panorama, o presente estudo tem por objetivo compreender quais as repercussões da revelação da orientação sexual nas relações familiares de jovens adultos homossexuais. Busca-se, dentro do paradigma da prática baseada em evidências - PBE (Mendes, Silveira, \& Galvão, 2008), reunir as melhores evidências empíricas para a compreensão desse 
fenômeno, priorizando as publicações em periódicos científicos de qualidade e, consequentemente, para fornecer suporte a intervenções e pesquisas nesse domínio.

\section{Método}

\section{Tipo de Estudo}

Trata-se de uma revisão integrativa da literatura nacional e internacional. A revisão integrativa tem por finalidade reunir e sintetizar resultados de pesquisas acerca de um determinado assunto ou tema, de modo sintetizado e ordenado, sendo uma das ferramentas mais empregadas no contexto da PBE. De acordo com as recomendações para a realização da revisão integrativa e partindo da busca pelas melhores evidências (Mendes et al., 2008), a questão norteadora do presente estudo foi definida a partir do método PICO ( $\mathrm{P}=$ participantes; $\mathrm{I}=$ intervenção; $\mathrm{C}=$ comparação; $\mathrm{O}=$ resultado; Santos, Pimenta, $\&$ Nobre, 2007). A pergunta formulada recebeu a seguinte redação: Quais as repercussões da revelação da orientação sexual $(\mathrm{O})$ nas relações familiares (I) de jovens adultos homossexuais (P)?

\section{Bases Indexadoras e Unitermos Empregados}

As bases empregadas foram LILACS, MEDLINE, PePSIC, PsycINFO e SciELO. Os descritores consultados foram: coming out, comportamento sexual, família, gays, homossexuais, homossexuais femininas, homossexuais masculinos, homossexualidade, LGBT, outness, rede de apoio, relações familiares, revelação da orientação sexual. A fim de justificar a escolha das nomenclaturas, destaca-se que a homossexual feminina - ou lésbica - é aquela "mulher que é atraída afetivamente e/ou sexualmente por pessoas do mesmo sexo/gênero" (Martins et al., 2010 , p. 14). O homossexual masculino é um homem que se sente atraído "sexual, emocional ou afetivamente por pessoas do mesmo sexo/gênero" (Martins et al., 2010, p. 14). Ainda para esses autores, a orientação sexual "refere-se à capacidade de cada pessoa de ter uma profunda atração emocional, afetiva ou sexual por indivíduos de gênero diferente, do mesmo gênero ou de mais de um gênero, assim como ter relações íntimas e sexuais com essas pessoas" (p. 10). No presente estudo, optou-se pela utilização do termo "orientação sexual", a fim de restringir as buscas apenas para os casos de descoberta da homossexualidade masculina ou feminina, não adentrando nos demais campos das sexualidades, como no caso de pessoas bissexuais ou transexuais/ transgêneros/travestis, por exemplo. Destas palavras, foram feitas combinações, para ampliar a busca dos dados. As combinações foram: homossexualidade $A N D$ relações familiares; gays $A N D$ rede de apoio; revelação da orientação sexual $A N D$ família; gays $A N D$ relações familiares; rede de apoio $A N D$ revelação da orientação sexual; coming out $A N D$ família. Vale ressaltar que os descritores homossexualidade, homossexuais, homossexuais femininas, homossexuais masculinos, gays, comportamento sexual, e relações familiares foram encontrados nos descritores BVS, de modo que os descritores LGBT, revelação da orientação sexual, família, rede de apoio, outness e coming out foram selecionados por meio de estudos que os utilizaram em suas palavras-chaves.

\section{Critérios de Inclusão e de Exclusão}

Os critérios de inclusão foram: (a) artigos indexados publicados em periódicos científicos, conforme recomendações do método de revisão a partir da PBE (Mendes et al., 2008); (b) redigidos nos idiomas português, inglês e espanhol; (c) publicados no período de janeiro de 2006 a maio de 2016; (d) com temática pertinente ao objetivo da revisão e que respondesse à questão norteadora. Artigos que não correspondiam ao objetivo do presente trabalho foram descartados, haja vista seu baixo grau de fornecimento de evidências para a prática. Os critérios de exclusão adotados foram: (a) livros, capítulos de livro, cartas, resenhas, notícias, anais de congressos, editoriais, dissertações e teses; (b) artigos publicados no período anterior a 2006; (c) estudos que se distanciem do objetivo e não respondam à questão norteadora; (d) artigos de revisão de literatura. 


\section{Procedimento}

Coleta de Dados. O levantamento dos dados foi realizado no mês de maio de 2016. Após as buscas iniciais, com os unitermos e suas combinações, foram aplicados os filtros dos critérios de inclusão e de exclusão. Os estudos, então, foram analisados novamente em termos de títulos e resumos, em um novo procedimento de filtragem de evidências, procedimento este realizado por dois juízes independentes. A partir desse crivo, os estudos foram recuperados e lidos na íntegra, a fim de proceder a uma nova seleção, agora mais pormenorizada e a partir do texto completo. Estes procedimentos foram realizados por dois juízes independentes, ambos psicólogos que trabalham com a temática. Os casos de discordância foram analisados por um terceiro juiz. Após esse processo, os artigos que compuseram o corpus foram reunidos, organizados em uma planilha em termos de títulos, autores, ano de publicação, objetivos, instrumentos, amostra, principais resultados, conclusões e limites/potencialidades. A partir desses elementos, os artigos foram discutidos, tendo em vista os procedimentos analíticos da revisão integrativa (Mendes et al., 2008).

Análise dos Dados. O corpus final foi organizado em uma planilha de Excel, destacando, para cada artigo recuperado na amostra final, os seguintes aspectos necessários para identificação do perfil das publicações: título, autores, instituição de origem dos autores, ano de publicação, periódico, objetivo, método/tipo de estudo, amostra, instrumentos, principais resultados, principais conclusões, limites e potencialidades/ contribuições e lacunas para novos estudos. A apresentação da revisão/síntese do conhecimento pautou-se nas recomendações do sistema PRISMA a partir dos critérios preconizados em sua lista de verificação (Moher, Liberati, Tetzlaff, Altman, \& PRISMA Group, 2009). Sendo assim, os artigos que compõem o corpus final foram analisados a fim de responder à questão norteadora. Foram elaboradas, mediante os resultados das pesquisas nas bases de dados e a questão norteadora, duas categorias, a fim de que, em cada uma delas, fossem discutidos os artigos que tenham temática semelhante. Vale ressaltar que não foram levados em consideração marcadores sociais para a seleção dos estudos, bem como este ponto não foi elencado para a composição do corpus e para a formação das categorias de análise. Desse modo, foram construídas as seguintes grandes categorias:

1. Homossexualidade e família: outness e o processo de coming out $\mathrm{e}$

2. A família diante do processo de coming out do(a) filho(a). Tais categorias serão exploradas na seção de Discussão.

\section{Resultados}

Os processos de busca, seleção e recuperação de evidências estão sumarizados no fluxograma (Figura 1). O corpus final foi composto por 38 artigos. $\mathrm{O}$ ano de maior evidência foi de 2014, com 21\% das publicações, seguido pelo ano de 2015 com 18\%. Nota-se que grande parte dos estudos (73\%) foram realizados após o ano de 2010, o que nos indica que a homossexualidade vem ganhando mais espaço e força na literatura científica nos últimos seis anos. Vale ressaltar também que os maiores números de publicações estão escritos e na língua inglesa (42\%), bem como a maioria foi realizada nos Estados Unidos. Este fator nos mostra que, na literatura internacional, a revelação da orientação sexual na família já está sendo pesquisada há mais tempo e há mais estudos acerca da temática.

A origem dos autores contemplou os países como Alemanha, Brasil, Canadá, Espanha, Estados Unidos, Israel, México, Porto Rico, Portugal e Turquia, sendo que o Brasil representa $44 \%$ da amostra. O periódico que mais apareceu entre as publicações foi Temas em Psicologia (7,8\%), seguido por Estudos de Psicologia (5,2\%) e Profissional Psychology: Research And Pratice $(5,2 \%)$. Os demais periódicos apareceram apenas uma vez cada, representando, assim, 2,6\% da amostra cada um. Nota-se que os estudos relacionados ao coming out estão sendo investigados no Brasil e publicados em periódicos ligados à Psicologia. Percebe-se que os estudos acerca do processo de revelação da orientação sexual ainda 


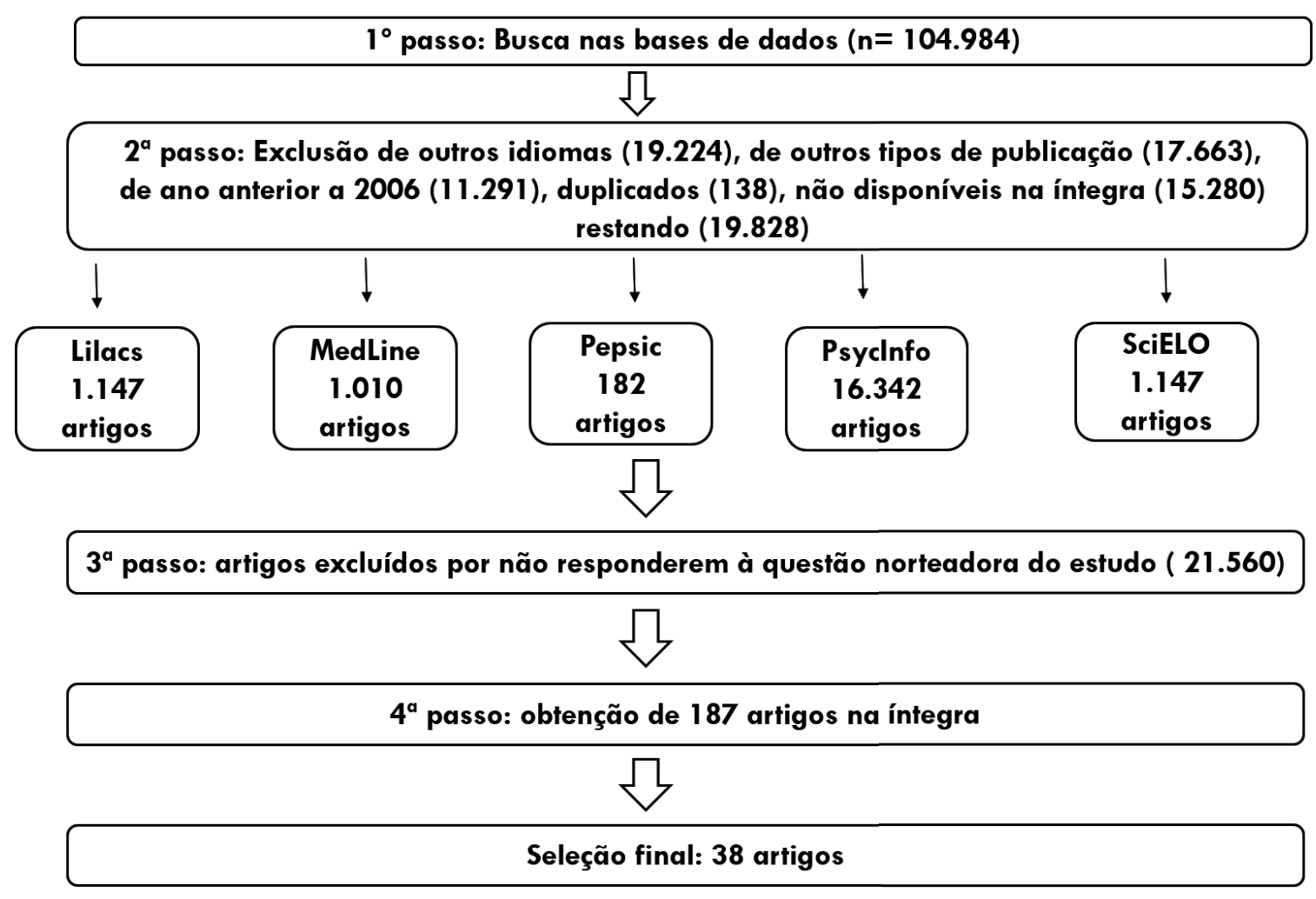

Procedimento de Seleção dos Artigos

Figura 1. Fluxograma de busca, seleção e elegibilidade dos estudos.

são poucos se comparados ao número de estudos relacionados à homossexualidade que, em sua maioria, abarcam questões ligadas temáticas como HIV e outras patologias, saúde pública, saúde mental, álcool e drogas, comportamento de risco, imagem corporal, suicídio, homoparentalidade, teoria queer, entre outras.

As investigações qualitativas representam $73,6 \%$ da amostra, sendo 26,4\% representando os estudos quantitativos. Em sua maioria, os estudos qualitativos utilizaram entrevistas semiestruturadas (Ceballos-Fernández, 2014; Etegoff \& Daiute, 2013; Soliva \& Silva, 2014), questionários (Poeschl, Venâncio, \& Costa, 2012) e processos clínicos (Diamond \& Shpigel, 2014; Frazão \& Rosário, 2008). Já os estudos quantitativos utilizaram, em sua maioria, escalas (Santos \& Fernandes, 2009) e questionários (Cadieux \& Chasteen, 2015).

Os principais objetivos dos artigos foram investigar as repercussões da homossexualidade na vida de gays e lésbicas (Ceballos-Fernández, 2014; Silva, Frutuoso, Feijó, Valerio, \& Chaves, 2015), compreender a dinâmica familiar duran- te o processo de coming out (Palma \& Levandowski, 2008; Santos, Brochado, \& Moscheta, 2007) e também os preconceitos enfrentados pelos homossexuais dentro e fora do contexto familiar (Santos \& Fernandes, 2009; Toledo \& Teixeira, 2013).

\section{Discussão}

\section{Homossexualidade e Família: Outness} e o Processo de Coming Out

Nota-se que os estudos selecionados abarcam a revelação da orientação sexual tanto de gays como também de lésbicas, nos contextos familiar, profissional e pessoal, permitindo conhecer e identificar questões ligadas ao processo de coming out - sua revelação ou ocultação da homossexualidade, também conhecido como o processo de "saída do armário". A "saída de armário" ou sua permanência nele pode ocasionar ao homossexual uma série de contrapontos, de modo que a revelação da orientação sexual pode ser baseada de acordo com o ambiente em que o sujeito estiver inserido, como, por exemplo, se o 
ambiente for acolhedor e receptivo, a revelação pode acontecer, se o ambiente for hostil, o "armário" poderá permanecer fechado neste caso (Miskolci, 2013; Silva \& Rodrigues, 2012). Desse modo, constata-se que nem sempre o coming out acontece, devido a questões que poderão ser elencadas nesta categoria. Identifica-se que estes grupos buscam apoio na sociedade visando se sentirem acolhidos para que revelem sua orientação sexual, sendo a família vista como a fonte de possível acolhimento de seus filhos, o que nem sempre ocorre e que pode favorecer que o indivíduo permaneça "no armário".

Para Guardarrama e Alfonso (2012), de acordo com a fala de homens homossexuais entrevistados, um dos pontos para a demora em "sair do armário" é a falta de informações e de discussões acerca da homossexualidade, o que retardou a revelação e o processo de aceitação dentro das famílias de cada participante. Já no estudo de Costa, Machado e Wagner (2015), os homossexuais entrevistados apresentaram maior tendência em revelar a orientação sexual para a família e amigos, confiantes de que seriam aceitos e que poderiam encontrar nestas pessoas um ponto de apoio e refúgio, não sendo vistos como possíveis fontes de preconceitos e discriminações. Para estes entrevistados, o preconceito só foi observado em ambientes externos ao familiar, como no trabalho.

Um ponto relevante é de que a família se preocupa com os preconceitos que o(a) filho(a) poderá sofrer, o que não garante que o preconceito não acontecerá dentro da própria casa. Há preconceitos velados, como, por exemplo, dizer que não discrimina o filho, mas que é bom que esta informação permaneça apenas entre eles, reforçando a tese da manutenção do segredo relacionado à intimidade dentro do ambiente privado, como se os afetos não pudessem ser visíveis na esfera pública (Miskolci, 2013).

A partir desses estudos (Costa et al., 2015; Guardarrama \& Alfonso, 2012), nota-se que, se houvessem mais discussões e informações acerca da homossexualidade, a possibilidade da quebra de paradigmas e preconceitos poderia ocorrer, de modo que tanto os homossexuais quanto suas famílias pudessem passar pelo processo de aceitação de forma menos dolorosa. Vale refletir, ainda, acerca da expectativa e da realidade vividas pelos(as) homossexuais que optam pelo processo de coming out, mesmo que seletivo, a fim de que possam buscar apoio em amigos ou instituições que os acolham, de fato, sem preconceitos.

Há que se considerar que, historicamente, criou-se a ideia de que a homossexualidade era uma sexualidade "indevida", sendo considerada subordinada aos outros grupos que possuem formas distintas de pôr em prática as suas sexualidades (Silva \& Strey, 2007). Foi pregada uma forma considerada "mais adequada" e "natural" de se praticar as relações sexuais, sendo considerado inadequado e pervertido tudo aquilo que fosse diferente da ideia inicial - a procriação. A homossexualidade, anteriormente chamada de homossexualismo - o que dá ideia de patologia - estava na lista de atos pervertidos (Lomando \& Wagner, 2009). Dessa forma, a American Psychology Association, em 1970, juntamente com o Conselho Federal de Medicina Brasileiro, em 1985, e com a Organização Mundial da Saúde (OMS), em 1993, passaram a não mais considerar a homossexualidade como um "desvio de transtorno sexual" e, diferentemente disso, constataram que a homossexualidade não se constitui como doença ou mesmo perversão (Mott, 2006), mas uma orientação (Martins et al., 2010).

Em estudo apenas com lésbicas, identificou-se que elas veem a família como um núcleo fundamental para a revelação da orientação sexual, uma vez que elas se sentem fortalecidas para lutarem por seus ideais, tendo como ponto de apoio o lar. Caso passem por alguma discriminação social devido à orientação sexual, as entrevistadas contam que, com o suporte oferecido por pais e mães, conseguem lutar por seus direitos. A família também é vista como fundamental para que o sujeito se sinta acolhido e amparado para revelar a orientação sexual, o que lhe dá forças também para que se revele no local de trabalho e em outros locais externos ao seu lar (Palma, Piason, Bezerra, \& Strey, 2010; Sabat, Trump, \& King, 2014). Observa-se que 
com o público masculino nem sempre o discurso é o mesmo, sendo a discriminação mais perceptível nas falas analisadas, o que também pode estar relacionado às questões de gênero (Costa et al., 2015; Simpson, Miranda, Mundo, \& Azevedo 2007).

Reforçando a ideia de discriminação no núcleo familiar e contradizendo o estudo de Costa et al. (2015), Palma e Levandowski (2008) encontraram, durante as entrevistas com mulheres lésbicas, a percepção de que as famílias reagiram de modo negativo diante do processo de coming out, e, em alguns casos, houve melhora na postura depois de algum tempo e, em outros, ainda há pais e mães que não aceitam a homossexualidade da filha, que é algo semelhante à realidade vivida por muitos homens entrevistados em outros estudos (Cadieux \& Chasteen, 2015; Guardarrama \& Alfonso, 2012). Tais reações negativas fizeram com que fossem pensadas em alternativas para ajudar tanto as lésbicas com suas famílias, como, por exemplo, atendimento psicológico para todos - pais e filhos -, de modo que colabore para a organização interna de toda a família.

Desse modo, o apoio psicológico para a família e para o(a) homossexual é essencial, a fim de que haja melhor compreensão e maior probabilidade da aceitação, tanto de quem revela, quanto para quem a recebe a informação. Estudos confirmaram o conflito entre pais e filhos após a revelação da orientação sexual, bem como ressaltaram que os apoios das redes são de suma importância para toda a família, a fim de que possam compreender e potencializar a aceitação da orientação do(a) filho(a) ou irmão(ã) (Arm, Horne, \& Levitt, 2009; Cadieux \& Chasteen, 2015; Jackson \& Mohr, 2016). Vale ressaltar que a aceitação também é um processo. A aceitação pode acontecer de modo imediato, aos poucos, ou não ocorrer, assim como o coming out, que pode ser dito para nenhuma pessoa, poucas pessoas ou para todas as pessoas do círculo de amizade, não necessariamente ao mesmo tempo.

Em estudo realizado por LaSala (2013), mediante realização de processo terapêutico familiar com os núcleos envolvidos na pesquisa, concluiu-se que houve um choque entre vida familiar e a homossexualidade masculina e fe- minina e que a convivência entre os progenitores de ambos os sexos e filhos gays ou lésbicas geraram uma série de conflitos por não haver aceitação da orientação sexual do(a) filho(a). Desse modo, atenta-se para o desejo de aceitação como um processo pode ser um mecanismo de menor frustração para os(as) homossexuais que sofreram rejeição por parte da família e da rede social, uma vez que, com o tempo, as situações podem passar por mudanças positivas. Por ser um processo, há possibilidade de que após um tempo indeterminado as situações mudem, assim como o(a) homossexual também pode se decidir revelar ou não sua orientação sexual para mais pessoas do que já possa ter revelado, destacando a noção do "armário" como um conceito fluido e em permanente movimentação (Miskolci, 2013; Sedgwick, 2007).

No estudo de Silva e Rodrigues (2012), nota-se o destaque para as dificuldades em "sair do armário", citando que a sociedade molda a identidade e, por isso, tal revelação é algo que pode acarretar sérias tensões pessoais, no trabalho e no âmbito familiar. Tais tensões favorecem que o sujeito não revele sua orientação sexual, podendo gerar, em um futuro breve, situações de desafeto não só para ele(a), mas também para as possíveis parcerias formadas. Os entrevistados relataram as dificuldades em não se revelarem devido às cobranças que a família e a sociedade têm, como casar, ter filhos e os tipos de lugares que costumam frequentar, como no estudo de Passamani (2015), em que os homens entrevistados relataram acerca da vivência de um casamento heterossexual, terem filhos e serem homossexuais, mantendo relações extraconjugais. Também é vista a "criação de armários", onde os indivíduos se escondem por detrás de conceitos sociais e religiosos, a fim de permanecerem "trancados em si" (Poeschl et al., 2012; Sedgwick, 2007; Solórzano \& Mendoza, 2014).

Vale destacar o estudo de Sedgwick (2007), na qual o autor retrata as questões ligadas ao manter-se no "armário" e o fato deste ser um assunto ainda não superado no que tange à abrangência de seus conhecimentos, ou seja, ainda há muito o que descobrir, vivenciar e conhecer acerca da homossexualidade e das questões li- 
gadas à sexualidade. O autor refere-se ao "armário" como algo que em alguns casos os homossexuais se veem obrigados a voltarem em determinadas circunstâncias de sua vida, como, por exemplo, diante de um novo emprego, de um certo grupo de amigos e de familiares. Sendo assim, a criação do armário surge de acordo com a necessidade do(a) homossexual sair ou voltar para dentro dele.

Para Silva e Nardi (2011), o judiciário tem papel fundamental para que todos se sintam livres para vivenciarem sua sexualidade, não havendo discriminações devido à orientação sexual. Sendo assim, pode-se observar que a revelação da orientação sexual se difere de família para família, se é uma revelação de homem ou mulher, e de modo geral, a homossexualidade ainda não é bem recebida pelas famílias, denotando uma imagem de "erro", de discriminação, de culpa de ambos os lados, tornando o momento ainda mais conflituoso para as famílias. E nas famílias em que a notícia foi bem acolhida, nota-se o fortalecimento dos laços, bem como o menor risco de conflitos internos e externos. São recomendados mais estudos que avaliem o coming out, de modo a fomentar que as famílias conheçam outras histórias semelhantes, promovendo uma cultura de aceitação e acolhimento a partir do reconhecimento da diversidade.

\section{A Família diante do Processo de Coming Out do(a) Filho(a)}

Estudos apontam que o processo de coming out de um(a) filho(a) pode acarretar diversas formas de violência dentro do âmbito familiar, podendo gerar situações de tensões diversas, ocasionando sofrimento psíquico e incertezas, o que contradiz, em muitos casos, as expectativas de acolhimento que o(a) jovem esperaria receber. Tem-se que o lar desses jovens acaba por ser o cenário de grandes conflitos, principalmente logo após a revelação da orientação sexual. Há uma tentativa da família em trazer o(a) jovem para a norma sexual hegemônica, o que traz mais sofrimento para todos os envolvidos. Um modo como os pais tentam resolver essa questão da revelação é por meio das violências física e psicológicas, o que pode colaborar para que a re- velação seja adiada ou ocultada, dependendo do caso. Essa dificuldade encontrada na tentativa da revelação acontecer ou não pode ocasionar a não revelação e as consequências emocionas podem ser as mais diversas, além de proporcionar uma série de frustrações ao(à) jovem por não ter relevado a orientação sexual. Portanto, o lar acaba sendo um local de contradições, uma vez que se espera que nele tenha-se o apoio e refúgio diante das discriminações vindas da sociedade. O preconceito dentro da própria casa pode ocasionar a ruptura do vínculo entre pais e filhos, o afastamento permanente ou definitivo e até mesmo a expulsão dos jovens de casa, o que costuma ser doloroso para todos (Ceballos-Fernández, 2014; Perucchi, Brandão, \& Vieira, 2014; Santos \& Fernandes, 2009; Soliva \& Silva, 2014).

Em estudo acerca do processo de aceitação de mães diante da revelação da orientação sexual do(a) filho(a), nota-se que os homossexuais que recebem apoio da família conseguem de forma mais serena lidar com as questões ligadas à sua sexualidade (Oksal, 2008). De modo geral, há dificuldades da família em aceitar a orientação sexual que foge do que é estabelecido pela cultura como sendo o "correto" - a heteronormatividade. Em relação às mães, é observado que elas podem passar pelo processo de invisibilidade da orientação sexual do(a) filho(a), na tentativa de fugir das possíveis preocupações diante do sofrimento deles(as). Um outro processo identificado é o da culpabilização, que pode ser diluído a partir da busca de informações dessas mães para saberem lidar e entender os processos dos seus (Hauer \& Guimarães, 2015). Tanto as preocupações quanto a culpa podem ser diluídas a partir do diálogo com os(as) próprios(as) filhos(as), como também com a busca da rede apoio em parentes, amigos ou até mesmo instituições que possam auxiliar nesse momento. E assim como o coming out é um processo para a família, a revelação da homossexualidade também é um processo para o(a) homossexual e, desta forma, necessita, muitas vezes, de tempo para ser refletido e, talvez, ser aceito.

No estudo de Lomando et al. (2011), assim como nos estudos anteriormente citados, observou-se a importância da família e dos amigos 
diante da revelação da orientação sexual. Para os autores, os meios de comunicação têm ajudado no processo de elaboração dos pais diante da realidade exposta, de modo que a mídia mostre a eles como se dão os processos de outness e coming out $\mathrm{e}$ a todo o processo que o homossexual enfrenta, tentando diluir nos pais e na sociedade uma possível visão que eles costumam ter dos filhos gays e lésbicas de que são desligados, de que não buscam se envolver para constituírem família e em alguns casos, são reconhecidos como anti-famílias.

A fim de ilustrar a importância da mídia perante a revelação da orientação sexual de um(a) filho(a), há um estudo que aborda a homossexualidade em uma determinada telenovela brasileira (Scorsolini-Comin \& Santos, 2012). A telenovela pode ser entendida como um veículo de informação aos pais que vivenciam a homossexualidade dentro de casa, dando a oportunidade de compreensão, de modo cênico, às vivências dos homossexuais, seus sofrimentos e a importância da família no acolhimento diante do coming out (Frazão \& Rosário, 2008; Hank \& Salzburger, 2015).

No estudo de Toledo e Teixeira (2013), nota-se que a sexualidade ainda é vista dentro das normas do século XIX, o que ocasiona diversos sofrimentos aos homossexuais. Foi observado que as entrevistas onde não houve a revelação da orientação sexual também não houve a discriminação na família. E nos casos em que houve a revelação, foram vivenciados momentos de homofobia intrafamiliar. Vale ressaltar que as pessoas que não contaram para a família notaram que haveria uma repressão caso contasse, o que o silêncio não deixa de ser uma forma de apreensão. Nesse sentido, Diamond e Shpigel (2014) sugerem que, se a família for agressiva, ficar "no armário" pode ser a melhor alternativa para evitar possíveis confrontos e atitudes negativas e buscar apoio de outras formas, como com amigos, grupos de apoio, em ONGs LGBTs e por meio de terapia individual. É importante mencionar que, mesmo permanecendo no "armário" para evitar conflitos familiares, buscar ajuda como os autores citam é de suma importância para a saúde física e mental do(a) jovem, a fim de que, mesmo não revelando para a família, consiga vivenciar sua sexualidade de acordo com sua orientação, não acatando ao modelo social empregado. Cuidar de si também é fazer valer seus direitos, mesmo que isso não seja revelado à família, como visto na pesquisa de Frost, Meyer e Schwartz (2016), na qual o apoio dos amigos e dos grupos LGBTs foram de suma importância para que houvesse menos estresse no cotidiano e mais qualidade de vida, independentemente do apoio ou não da família.

Na visão de Santos, Brochado, et al. (2007), as famílias acabam reagindo de modo a estranhar a revelação, podem se sentir traídos pelos filhos por acharem que os conheciam de modo íntimo, mas que no fundo "escondiam" algo deles, além de pensarem na escolha "errada" que foi feita. Veem a homossexualidade como um castigo, sentimento de culpa por acreditam que o(a) filho(a) "preferiu" ser gay devido a um possível erro na educação que lhe foi dada. Constata-se uma falta de acolhimento pela família, o que proporciona ao homossexual um sentimento de inferioridade e baixa autoestima, acarretando prejuízos em outros lugares, como escola e trabalho (Guarnero, 2007). Vale ressaltar a importância da aceitação por parte da família, uma vez que esta, assim como no estudo citado anteriormente, auxilia na autoestima dos gays e lésbicas, além de ser referência de apoio social e colaborar para que tenha boa saúde de modo geral. $\mathrm{O}$ apoio da família protege contra uma possível depressão e uso de substâncias como álcool e drogas, afastando de comportamentos de risco e de ideações suicidas (Feinstein, Wadsworth, Davila \& Goldfriel, 2014; Ryan, Russell, Huebner, Diaz, \& Sanchez, 2010). Contudo, a aceitação pode não acontecer na família e mesmo diante desta possibilidade, cabe ao(à) homossexual lidar com a sexualidade e com o contexto familiar de modo que não se anule, o que geralmente é um processo difícil que pode acarretar desgaste físico e emocional.

Diversos autores exploram que as famílias, tanto quanto os jovens, necessitam de apoio para conseguirem caminhar de modo que convivam bem com a revelação da orientação sexual do sujeito. Estes autores reforçam a importância da rede de apoio que abarque os amigos, parentes, 
psicólogos e também a religião. Nota-se que as famílias que receberam este tipo de apoio conseguiram lidar melhor com as mudanças no ambiente familiar (Etengoff \& Daiute, 2013; Puckett, Woodward, Mereish, \& Pantalone, 2015). Em famílias mais adaptáveis a revelação é mais tranquila, com maior possibilidade de acolhimento (Robinson \& Brewster, 2016; Silva et al., 2015; Willoughby, Malik, \& Lindahl, 2006).

A partir desse corpo de literatura analisado, podemos observar que o processo de coming out varia de família para família e, muitas vezes, não se pode prever qual será a reação do núcleo familiar diante da informação. Na tentativa de explicação das mais variadas expressões e reações pode-se recuperar diversas variáveis contextuais (micro e macrossociais), de história da família e mesmo de maior ou menor disponibilidade para o diálogo acerca das sexualidades. A rede de apoio social tem sido apontada como de suma importância nesse processo para auxiliar na possível nova dinâmica familiar após a revelação.

\section{Considerações Finais}

A revelação da orientação sexual, em muitos casos, é um processo conflituoso tanto para quem faz a revelação, como também para quem recebe a informação. Nota-se que, nos estudos analisados, grande parte ressalta a negação da família diante do coming out, ocasionando diversas dificuldades para o(a) homossexual. De modo geral, as mães ganham o papel de aceitarem mais facilmente seus(suas) filhos(as) diante da revelação, enquanto os pais negam em maior parte, principalmente se tratando de filhos homossexuais. Outro fator relevante são os modos como cada família consegue se organizar para buscar apoio e também para apoiar seu(sua) filho(a), sendo que até a religião contribuiu para a aceitação.

Independente do país onde a pesquisa foi realizada, observa-se a presença da negação e dos conflitos, e, por consequência, as dificuldades encontradas pelo(a) homossexual que, além de sofrer com o preconceito na sociedade, também passa por situações não acolhedoras dentro da própria família. Em contrapartida, há casos em que a família acolheu seu(sua) filho(a), de modo que o(a) fez sentir pertencente, de fato, àquela família. Em outros casos, o sujeito teve de buscar ajuda em outras redes de apoio, e em muitos casos, a depressão e o uso de drogas psicoativas fizeram parte desse roteiro, inclusive com ideações suicidas.

O presente estudo conseguiu responder sua questão norteadora, que era "Quais as repercussões da revelação da orientação sexual na família?". Pode-se observar que as repercussões não costumam ser acolhedoras no início, mas que vão ganhando espaço com o passar do tempo, em alguns casos. Há um choque inicial, que faz com que pais e mães neguem a realidade, proporcionando ao homossexual um período de intensa luta interna, gerando sentimentos de negação, culpabilização, medo, revolta, vergonha e que, depois de um tempo e em famílias que são abertas à realidade, esses sentimentos são abandonados e os novos são de pertencimento e de ser aceito em sua própria família.

Nota-se que grande parte dos estudos analisa o processo de coming out por meio da fala do(a) jovem que revelou a orientação sexual à família, de modo que poucos os estudos revisados deram espaço para escuta dos pais, mães e irmãos, a fim de conhecer também o ponto de vista deles diante do processo. Outro fator relevante é a rede de apoio social que não é citada em muitos dos estudos e que pode ser interessante conhecê-la para verificar se houve ou não a presença de pessoas do convívio ou novos personagens na vida do participante de modo ativo, direta ou indiretamente, agindo no processo de coming out.

Sugere-se que novos estudos empíricos sejam realizados acerca da temática, a fim de dar voz a essas famílias e aos homossexuais, o que também pode contribuir para a criação de redes de apoio e acolhimento aos envolvidos, bem como para compreender como tais "armários" são criados, recriados, deslocados e transformados social e culturalmente no processo de desenvolvimento. Apreender essa movimentação dos conceitos e a noção de processo (nem sempre contínuo) parece ser uma necessidade premente nos estudos empíricos analisados, em uma pro- 
posta mais fluida e aberta a reflexões constantes. Políticas de atenção a essa população podem se concentrar nos processos de coming out, promovendo uma escuta clínica que proporcionem maior aceitação e, consequentemente, maior sentimento de pertença, integração e qualidade de vida.

\section{Authors' Contributions}

Contribuição substancial no conceito e desenho do estudo: Geysa Cristina Marcelino Nascimento and Fabio Scorsolini-Comin.

Contribuição na coleta de dados: Geysa Cristina Marcelino Nascimento.

Contribuição na análise e interpretação de dados: Geysa Cristina Marcelino Nascimento and Fabio Scorsolini-Comin.

Contribuição para a preparação do manuscrito: Geysa Cristina Marcelino Nascimento and Fabio Scorsolini-Comin.

Contribuição à revisão crítica, agregando conteúdo intelectual: Geysa Cristina Marcelino Nascimento and Fabio Scorsolini-Comin.

\section{Conflitos de interesse}

Os autores declaram não ter conflito de interesse relacionado à publicação deste manuscrito.

\section{Referências}

Arm, J. A., Horne, S. G., \& Levitt, H. M. (2009). Negotiating connection to GLBT experience: Family members'experience of anti-glbt movements and policies. Journal of Counseling Psychology, 56(1), 82-96. doi: http://dx.doi.org/10.1037/ a0012813

Balsam, K. F., \& Mohr, J. J. (2007). Adaptation to sexual orientation stigma: A comparison of bisexual and lesbian/gay adults. Journal of Counseling Psychology, 54(3), 306-319. doi: http:// dx.doi.org/10.1037/0022-0167.54.3.306

Butler, J. (2003). Problemas de gênero: Feminismo e subversão da identidade. Rio de Janeiro, RJ: Civilização Brasileira.

Cadieux, J., \& Chasteen, A. L. (2015). You gay, bro? Social costs faced by male confronters of antigay prejudice. Psychology Of Sexual Orienta- tion And Gender Diversity, 2(4), 436-446. doi: http://dx.doi.org/10.1037/sgd0000134

Ceballos-Fernández, M. (2014). Identidad homosexual y contexto familiar heteroparental: implicaciones educativas para la subversión social. Revista Latinoamericana De Ciencias Sociales, 12(2), 643-658. doi: http://dx.doi.org/10.11600/ $1692715 x .1229140514$

Corliss, H. L., Austin, S. B., Roberts, A. L., \& Molnar, B. E. (2009). Sexual risk in "mostly heterosexual" young women: influence of social support and caregiver mental health. Journal of Women's Health, 18(12), 2005-2010.

Costa, C. B., Machado, M. R., \& Wagner, M. F. (2015). Percepções do homossexual masculino: Sociedade, família e amizades. Temas em Psicologia, 23(3), 777-788. doi: http://dx.doi. org/10.9788/TP2015.3-20

Detrie, P. M., \& Lease, S. H. (2007). The relation of social support, connectedness, and collective self-esteem to the psychological well-being of lesbian, gay, and bisexual youth. Journal of Homosexuality, 53(4), 173-199.

Diamond, G. M., \& Shpigel, M. S. (2014). Attachment-based family therapy for lesbian and gay young adults and theis persistently nonaccepting parents. Professional Psychology: Research and Practice, 45(4), 258-268. doi: 10.1037/ a0026247

Etengoff, C., \& Daiute, C. (2013). Family menber's uses of religion in post-coming-out conflicts with their gay relative. Psychology of Religion and Spirituality, 6(1), 33-43.

Feinstein, B. A., Wadsworth, L. P., Davila, J., \& Goldfried, M. R. (2014). Do parental acceptance and family support moderate associations between dimensions of minority stress and depressive symptoms among lesbians and gay men? Professional Psychology: Research and Practice, 45(4), 239-246. doi: http://dx.doi.org/10.1037/ a0035393

Frazão, P., \& Rosário, R. (2008). O coming out de gays e lésbicas e as relações familiares. Análise Psicológica, 26, 25-45.

Frost, D. M., Meyer, I. H., \& Schwartz, S. (2016). Social support networks among diverse sexual minority populations. American Journal of Orthopsychiatry, 86, 91-102. doi: 10.1037/ ort0000117 
Guardarrama, J. G., \& Alfonso, J. T. (2012). El significado de la experiencia de la aceptación de la orientación sexual homosexual desde la memoria de un grupo de hombres adultos puertorriqueños. Revista Eureka, 9(2), 158-170.

Guarnero, P. A. (2007). Family and community influences on the social and sexual lives of latino gay men. Journal of Transcultural Nursing, 18(1), 12-18.

Hank, K., \& Salzburger, V. (2015). Gay and lesbian adults' relationship with parents in Germany. Journal Of Marriage And Family, 77, 866-876. doi: https://doi.org/10.1111/jomf.12205

Hauer, M., \& Guimarães, R. S. (2015). Mães, filh@s e homossexualidade: Narrativas de aceitação. Temas em Psicologia, 23(3), 649-662. doi: http://dx.doi.org/10.9788/TP2015.3-10

Jackson, S. D., \& Mohr, J. (2016). Conceptualizing the closet: Differentiating stigma concealment and nondisclosure processes. Psychology of Sexual Orientation and Gender Diversity, 3(1), 80-92. doi: http://dx.doi.org/10.1037/sgd0000147

LaSala, M. C. (2013). Out of the darkness: Three waves of family research and the emergence of family therapy for lesbian and gay people. Clinical Socil Work Journal, 41, 267-276.

Lomando, E., \& Wagner, A. (2009). Reflexões sobre termos e conceitos das relações entre pessoas do mesmo sexo. Revista Sociais e Humanas, 22(2), $1-18$.

Lomando, E., Wagner, A., \& Gonçalves, J. (2011). Coesão e adaptabilidade e rede social no relacionamento conjugal homossexual. Psicologia: Teoria e Prática, 13(3), 95-109.

Maffesoli, M. (2007). Homossocialidade: Da identidade às identificações. Bagoas: Estudos Gays: Gêneros E Sexualidades, 1(1), 15-25.

Martins, F., Romão, L., Lindner, L., \& Reis, T. (2010). Manual de Comunicação LGBT. Curitiba, PR: Ajir Artes Gráficas.

Méllo, R. P. (2012). Corpos, heteronormatividade e performances híbridas. Psicologia e Sociedade, 24(1), 197-207. doi: http://dx.doi.org/10.1590/ S0102-71822012000100022

Mendes, K. D. S., Silveira, R. C. C. P., \& Galvão, C. M. (2008). Revisão Integrativa: Método de pesquisa para a incorporação de evidências na saúde e na enfermagem. Texto \& Contexto Enfermagem, 17(4), 758-764. doi: http://dx.doi. org/10.1590/S0104-07072008000400018
Meyer, I. H. (2003). Prejudice, social stress, and mental health in lesbian, gay, and bisexual populations: Conceptual issues and research evidence. Psychological Bulletin, 129, 674-697.

Miskolci, R. (2013). Machos e brothers: Uma etnografia sobre o armário em relações homoeróticas masculinas criadas on-line. Revista Estudos Feministas, 21(1), 301-324. doi: http://dx.doi. org/10.1590/S0104-026X2013000100016

Miskolci, R. (2015). "Discreto e fora do meio" - Notas sobre a visibilidade sexual contemporânea. Cadernos Pagu, (44), 61-90.

Moher, D., Liberati, A., Tetzlaff, J., Altman, D. G., \& the PRISMA Group. (2009). Preferred reporting items for systematic reviews and meta-analyses: The PRISMA statement. Annals of Internal Medicine, 151(4), 264-269. doi: 10.1371/journal. pmed.1000097

Mott, L. (2006). Homoafetividade e direitos humanos. Revista de Estudos Femininos, 14(2), 509-521. doi: http://dx.doi.org/10.1590/S0104-026 X2006000200011

Nascimento, G. C. M., Scorsolini-Comin, F., Fontaine, A. M. G. V., \& Santos, M. A. (2015). Relacionamentos amorosos e homossexualidade: Revisão integrativa da literatura. Temas em Psicologia, 23(3), 547-563. doi: http://dx.doi. org/10.9788/TP2015.3-03

Oksal, A. (2008). Turkish family members' attitudes toward lesbians and gay men. Sex Roles, 58, 514-525. doi: https://doi.org/10.1007/s11199007-9370-6

Palma, Y. A., \& Levandowski, D. C. (2008). Vivências pessoais e familiares de homossexuais femininas. Psicologia em Estudo, 13(4), 771-779.

Palma, Y. A., Piason, A. S., Bezerra, A. C. M., \& Strey, M. N. (2010). Experiências de vida e os processos de visibilidade social de mulheres que amam mulheres. Aletheia, 33, 1-13.

Passamani, G. R. (2015). O casamento como “armário": Histórias de um homem com conduta homossexual no Pantanal de Mato Grosso do Sul. Sexulidad, Salud y Sociedad - Revista Latinoamericana, 21, 111-135. doi: http://dx.doi. org/10.1590/1984-6487.sess.2015.21.07.a

Perucchi, J., Brandão, B. C., \& Vieira, H. I. S. (2014). Aspectos psicossociais da homofobia intrafamiliar e saúde de jovens lésbicas e gays. Estudos de Psicologia (Natal), 19(1), 
67-76. doi: http://dx.doi.org/10.1590/S1413$-294 X 2014000100009$

Poeschl, G., Venâncio, J., \& Costa, D. (2012). Consequências da (não) revelação da homossexualidade e preconceito sexual: O ponto de vista das pessoas homossexuais. Revista Psicologia, 26(1), 33-53.

Prado, M. A. M., \& Machado, F. V. (2012). Preconceito contra homossexualidades: A hierarquia da invisibilidade. São Paulo, SP: Cortez.

Puckett, J. A., Woodward, E. N., Meireish, E. H., \& Pantalone, D. W. (2015). Parental rejection following sexual orientation disclosure: Impact on internalized homophobia, social support, and mental health. LGBT Health, 2(3), 265-269. doi: 10.1089/lgbt.2013.0024

Robinson, M. A., \& Brewster, M. E. (2016). Understanding affiliate stigma faced by heterosexual family and friends of lgb people: A measurement development study. Journal of Family Psychology, 30(3), 353-363. doi: http://dx.doi. org/10.1037/fam0000153

Rosario, M., Schrimshaw, E. W., \& Hunter, J. (2011). Different patterns of sexual identity development over time: Implications for the psychological adjustment of lesbian, gay, and bisexual youths. Journal of Sex Research, 48(1), 3-15. doi: 10.1080/00224490903331067

Ryan, C., Russell, S. T., Huebner, D., Diaz, R., \& Sanchez, J. (2010). Family acceptance in adolescence and the health of lgbt young adults. Journal of Child and Adolescent Psychiatric Nursing, 23(4) 205-213.

Sabat, I., Trump, R., \& King, E. (2014). Individual, interpersonal, and contextual factors relating to disclosure decisions of lesbian, gay, and bisexual individuals. Psychology of Sexual Orientation and Gender Diversity, 1(4), 431-440. doi: http:// dx.doi.org/10.1037/sgd0000061

Santos, A. F., \& Fernandes, S. C. S. (2009). Enfrentamento, locus de controle e preconceito: Um estudo com pessoas de orientação homoafetiva. Psicologia em Revista (Maringá), 15(3), 101119.

Santos, C. M. C., Pimenta, C. A. M., \& Nobre, M. R. C. (2007). A estratégia PICO para a construção da pergunta de pesquisa e busca de evidência. Revista Latino-Americana de Enfermagem, 15(3), 508-511. doi: http://dx.doi.org/10.1590/ S0104-11692007000300023
Santos, M. A., Brochado, J. U., Jr., \& Moscheta, M. S. (2007). Grupo de pais de jovens homossexuais. Revista Eletrônica Saúde Mental Álcool e Drogas, 3(2), 1-16.

Sedgwick, E. K. (2007). A epistemologia do armário. Cadernos Pagu, 17, 19-54.

Scorsolini-Comin, F., \& Santos, M. A. (2012). Insensatos afetos: Homossexualidade e homofobia na telenovela brasileira. Barbarói, 36, 50-66.

Silva, F. R., \& Nardi, H. C. (2011). A construção social e política pela não discriminação por orientação sexual. Revista de Saúde Coletiva, 21(1), 251-265. doi: http://dx.doi.org/10.1590/ S0103-73312011000100015

Silva, M. M. L., Frutuoso, J. F. F., Feijó, M. R., Valerio, N. I., \& Chaves, U. H. (2015). Família e orientação sexual: Dificuldades na aceitação da homossexualidade masculina. Temas em Psicologia, 23(3), 677-692. doi: http://dx.doi. org/10.9788/TP2015.3-12

Silva, M. R. S., \& Rodrigues, C. I. (2012). Digressões homossexuais: Notas antropológicas sobre $\mathrm{co}^{-}$ ming out, ethos LGBT e bajubá em Belém-PA. Revista NUFEN, 4(1), 44-58.

Silva, J., Neto, \& Strey, M. (2007). Gênero e conjugalidade: encontros e desencontros na representação social da relação conjugal. In M. Strey, J. A. Silva Neto, \& L. Horta. Família e Gênero (pp. 170-185). Porto Alegre, RS: Editora da Pontifícia Universidade Católica do Rio Grande do Sul.

Simpson, C. A., Miranda, F. A. N., Mundo, M. M. S., \& Azevedo, D. M. (2007). Trajetória de vida de um homossexual: Entre o silêncio e a opressão. Ciência e Cuidado em Saúde, 6(4), 424-432. doi: http://dx.doi.org/10.4025/cienccuidsaude. v6i4.3669

Soliva, T. B., \& Silva, J. B., Jr., (2014). Entre revelar e esconder: Pais e filhos em face da descoberta da homossexualidade. Sexualidad, Salud $Y$ Sociedad - Revista Latinoamericana, 17, 124148. doi: http://dx.doi.org/10.1590/1984-6487. sess.2014.17.08.a

Solórzano, A. J., \& Mendoza, M. R. (2014). "Salir del clóset" en la Ciudad de México. Revista Salud Mental, 37(5), 391-397.

Toledo, L. G., \& Teixeira, F. S., Filho. (2013). Homofobia familiar: Abrindo o armário 'entre quatro paredes'. Arquivos Brasileiros de Psicologia, 65(3), 376-391. 
Victora, C., \& Knauth, D. R. (2004). Corpo, gênero e saúde: A contribuição da antropologia. In M. N. Strey \& S. T. L. Cabeda (Eds.), Corpos e subjetividade em exercicio interdisciplinar (pp. 81-91). Porto Alegre, RS: Editora da Pontifícia Universidade Católica do Rio Grande do Sul.

Willoughby, B. L. B, Malik, N. M., \& Lindahl, K. M. (2006). Parental reactions to their sons' sexual orientation disclosures: The roles of family cohesion, adaptability, and parenting style. Psychology of Men \& Masculinity, 7(1), 14-26. doi: 10.1037/1524-9220.7.1.14
Zimmerman, L., Darnell, D. A., Rhew, I. C., Lee, C. M., \& Kaysen, D. (2015). Resilience in community: A social ecological development model for young adult sexual minority women. American Journal of Community Psychology, 55(1-2), 179-190. doi: 10.1007/s10464-015-9702-6

Recebido: $17 / 04 / 2017$

$1^{a}$ revisão: $23 / 05 / 2017$

Aceite final: 23/05/2017

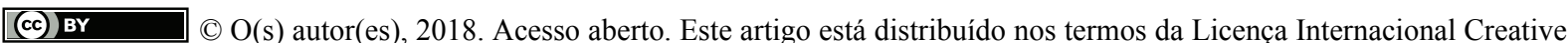
Commons Atribuição 4.0 (http://creativecommons.org/licenses/by/4.0/), que permite o uso, distribuição e reprodução sem restrições em qualquer meio, desde que você dê crédito apropriado ao(s) autor(es) original(ais) e à fonte, fornecer um link para a licença Creative Commons e indicar se as alterações foram feitas. 